\title{
Overwork-related disorders in Japan: recent trends and development of a national policy to promote preventive measures
}

\author{
Takashi YAMAUCHI ${ }^{1 *}$, Toru YOSHIKAWA ${ }^{1}$, Masahiro TAKAMOTO ${ }^{2}$, Takeshi SASAKI ${ }^{1}$, \\ Shun MATSUMOTO ${ }^{1}$, Kotaro KAYASHIMA ${ }^{1}$, Tadashi TAKESHIMA ${ }^{3}$ and \\ Masaya TAKAHASHI ${ }^{1}$
}

\author{
${ }^{1}$ Research Center for Overwork-Related Disorders, National Institute of Occupational Safety and Health, Japan \\ ${ }^{2}$ College of Education, Yokohama National University, Japan \\ ${ }^{3}$ Kawasaki City Center for Mental Health and Welfare, Japan
}

Received November 10, 2016 and accepted January 23, 2017

Published online in J-STAGE January 31, 2017

\begin{abstract}
Overwork-related disorders, such as cerebrovascular/cardiovascular diseases (CCVD) and mental disorders due to overwork, are a major occupational and public health issue worldwide, particularly in East Asian countries. This report discusses the recent trend of overwork-related disorders in Japan from the perspective of workers' compensated occupational diseases, as well as the development of a national policy for preventive measures against overwork-related disorders in Japan. Recently, the number of claimed and compensated cases of occupational mental disorders has increased substantially, particularly among young workers, as compared to those of occupational CCVD. In response to these situations and action from society, the Japanese Government passed the "Act on Promotion of Preventive Measures against Karoshi and Other Overwork-Related Health Disorders" in June 2014 to develop a national initiative towards the prevention of overwork-related disorders. Changes in the trend of overwork-related disorders in Japan under a legal foundation and an initiative by the central government should be closely monitored so that other countries can benefit from the experiences.
\end{abstract}

Key words: Cardiovascular diseases, Cerebrovascular diseases, Japan, Mental disorders, National strategies, Overwork, Work stress

\section{Introduction}

Overwork-related disorders, including karoshi (i.e., death by cerebrovascular and cardiovascular diseases (CCVD) due to overwork) and karojisatsu (i.e., suicide due to overwork), constitute a major occupational and public health issue worldwide ${ }^{1)}$, particularly in East Asian countries $^{2)}$, including Japan ${ }^{3)}$. In 2015, the average annual

*To whom correspondence should be addressed.

E-mail: yamat.fw@gmail.com

(C)2017 National Institute of Occupational Safety and Health working hours among employed people in Japan was $1,938.6 \mathrm{~h}^{4}$. On the other hand, regardless of gender, the proportion of workers who were working $49 \mathrm{~h}$ or more per week in Japan in 2014 (30.0\% in men and 9.7\% in women) was higher than that in western developed countries ${ }^{5,6)}$, suggesting that long working hours are more prevalent in Japan. In addition, whereas CCVD and mental disorders attributed to heavy workloads or stressful work events are considered compensable occupational diseases by workers' compensation insurance systems in Japan, Korea, and Taiwan, the number of compensated cases and these trends are different ${ }^{2}$. 
According to the National Police Agency of Japan ${ }^{7}$, 24,025 people died by suicide in Japan in 2015 and, of these suicide completers, reasons for suicide could be determined in 17,981 (74.8\%). Among those, 2,159 (12.0\%) completed suicide due to "work-related issues," including suicidal cases due to "exhaustion due to overwork" (i.e., karojisatsu). Recently, suicide rates due to work-related issues, such as stress involved in long working hours and heavy workloads, have increased among people aged 20 to $29 \mathrm{yr}^{8)}$. Furthermore, as compared to occupational CCVD, occupational mental disorders have been compensated more frequently among young employees in Japan ${ }^{9)}$.

In the present paper, we aimed to discuss the recent trend of overwork-related disorders in Japan from the perspective of workers' compensated occupational diseases (i.e., CCVD and mental disorders) due to overwork, as well as the development of a national policy for the promotion of preventive measures against overwork-related disorders in Japan.

\section{Compensated Occupational CCVD and Mental Disorders in Japan}

To our knowledge, the first reported case of overworkrelated disorders in Japan occurred in 1969, which was a case of death by stroke ${ }^{10,11)}$. In addition, the first case of occupational mental disorders was compensated in $1984^{12}$. Following changes in the awareness of overwork-related disorders in society and decisions made in the suits, since 1988, the Ministry of Health, Labour and Welfare (MHLW) of Japan has provided the annual number of cases of both claimed and compensated occupational CCVD and mental disorders $\left.{ }^{9}, 13\right)$.

Figure 1-(a) shows the trend of claimed and compensated cases of occupational CCVD in Japan between fiscal years 1988 and $2015^{9,13)}$. In 2002, the number of compensated occupational CCVD cases increased sharply. Over the last three fiscal years, nearly 800 claims for compensation of occupational CCVD have been made and, of these, about one third were compensated.

The sharp increase in the number of compensated CCVD cases in 2002 may be due to the relaxation of the definition of heavy workloads in the amendment of certification criteria by the MHLW in December $2001^{2,3)}$. Regarding this amendment, the expert committee on the criteria for compensation of occupational CCVD, which was organized by the MHLW, published a report on the association between overwork and occupational CCVD in November 2001. Based on this report, the standards of overtime working

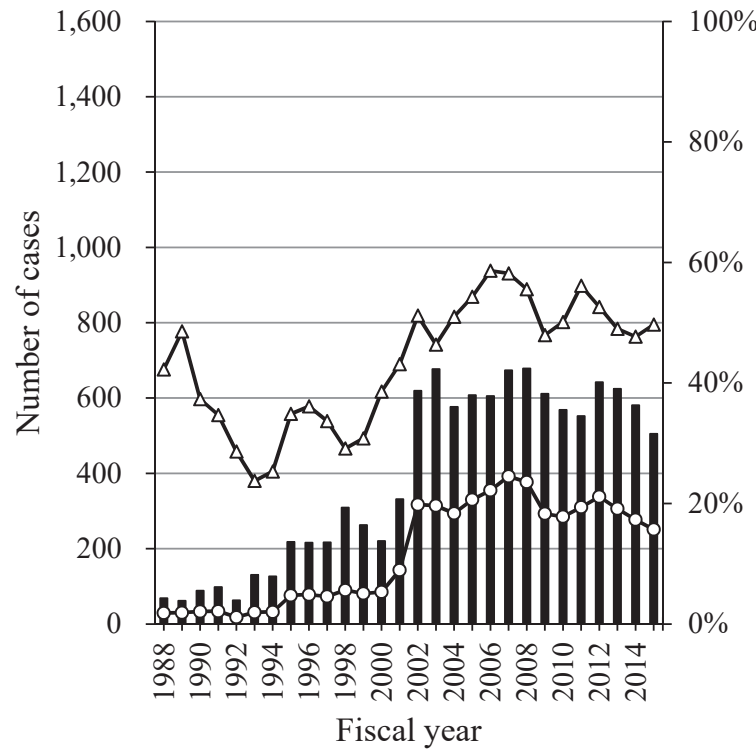

$\longrightarrow$ Compensation rate $(\%) \multimap$ Claimed cases
$\neg$ Compensated cases

Fig. 1-(a). Number of claimed and compensated cases of occupational cardiovascular disease, FY1988-FY2015.

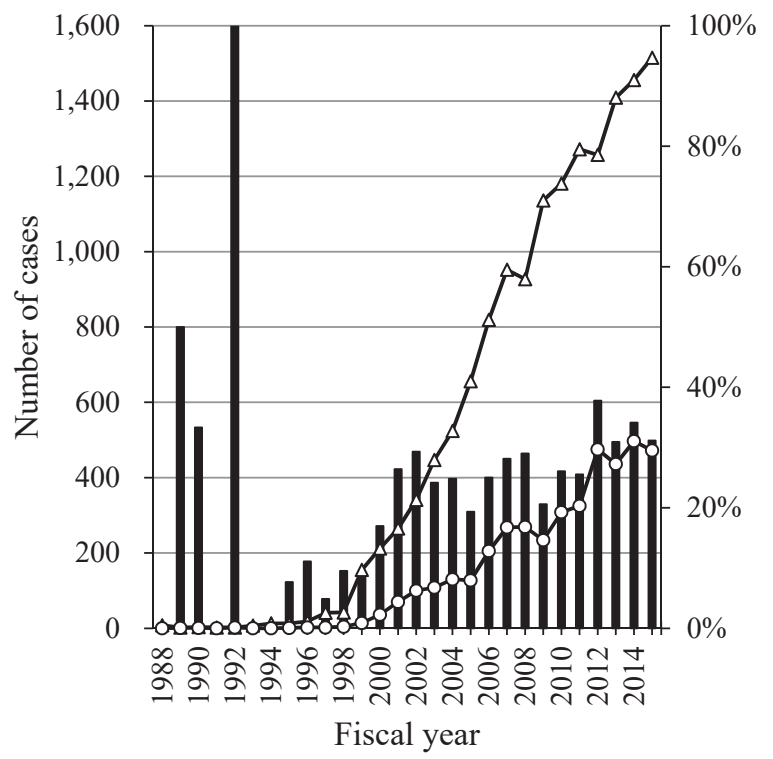

$\square$ Compensation rate $(\%) \multimap$ Claimed cases
$-\sim$ Compensated cases

Fig. 1-(b). Number of claimed and compensated cases of occupational mental disorders, FY1988-FY2015.

hours for the compensation of occupational CCVD were established in a more quantitative manner as follows: (1) overtime working hours of more than $100 \mathrm{~h}$ per month for the past month before the onset of CCVD, and (2) overtime working hours of more than $80 \mathrm{~h}$ per month for the 
past 2 to 6 months before the onset of $\mathrm{CCVD}^{3)}$.

Figure 1-(b) shows the trend of claimed and compensated cases of occupational mental disorders in Japan between fiscal years 1988 and 2015, 13). In 1999, the number of applications for compensation jumped sharply, possibly due to the establishment of the guideline for compensation of occupational mental disorders by the MHLW. Since 1999, both the number of claimed and compensated cases have increased substantially. Compensation rate (the number of compensated cases divided by the total number of claims) has also increased from $9.0 \%$ in 1999 to $29.3 \%$ in 2002, and has remained at about $30 \%$ in recent years.

As shown in Fig. 2, the proportion of suicidal cases among those who had claimed compensation for occupational mental disorders was $60 \%$ in 1999 . Since 1999 , the proportion has substantially decreased due to the dramatic increase in the total number of claimed cases for compensation and, after 2007, it has remained at about $15 \%$. Similarly, the proportion of suicidal cases among those who were determined to be compensated decreased after 1999, and it has remained at nearly $20 \%$ (Fig. 3).

In 2002, the MHLW launched the first comprehensive program for the prevention of health impairment due to overwork $^{12)}$. It included the following three major focus areas: (1) reduction of overtime work to $45 \mathrm{~h}$ or less per month, (2) introduction of medical examinations for all workers, and (3) offer of consultation with and health guidance by a doctor for those who work long hours ${ }^{3,10)}$. In addition, the MHLW have implemented some preventive measures regarding mental health promotion in the workplace and prevention of workplace bullying and power harassment $^{14)}$

However, these programs and efforts by the Government of Japan to prevent overwork-related disorders may not have been successful in reducing overwork-related disorders. As argued in previous literature ${ }^{10)}$, that may be due to (1) the attitudes among the Japanese workers towards long working hours, (2) the complexity of risk factors for overwork-related disorders other than long working hours and work environment, such as shift work, business practice, and lifestyle, and (3) low awareness of the impact of long working hours on health among the public. In terms of working hours, whereas average annual working hours among workers (including part-time workers) in Japan have gradually decreased from 1,920 h in 1993 to $1,734 \mathrm{~h}$ in 2015 , those among full-time workers have remained at approximately $2,000 \mathrm{~h}^{14}$. Furthermore, despite the increase in awareness of overwork-related disorders in society and the number of cases of occupational disorders,

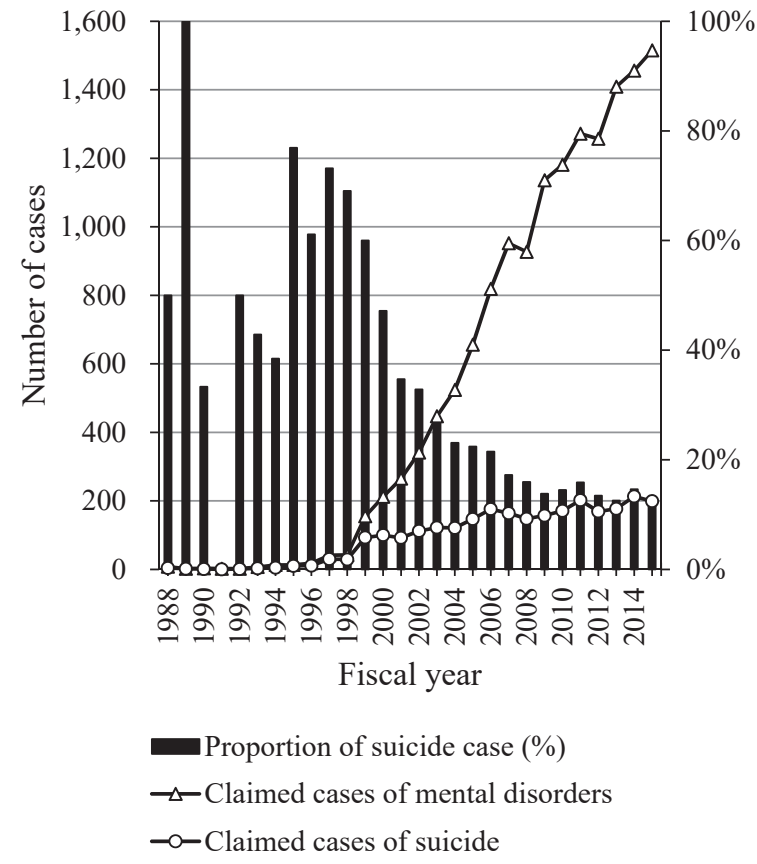

Fig. 2. Proportion of suicide cases among the claimed cases of occupational mental disorders claimed between fiscal years 1988 and 2015.

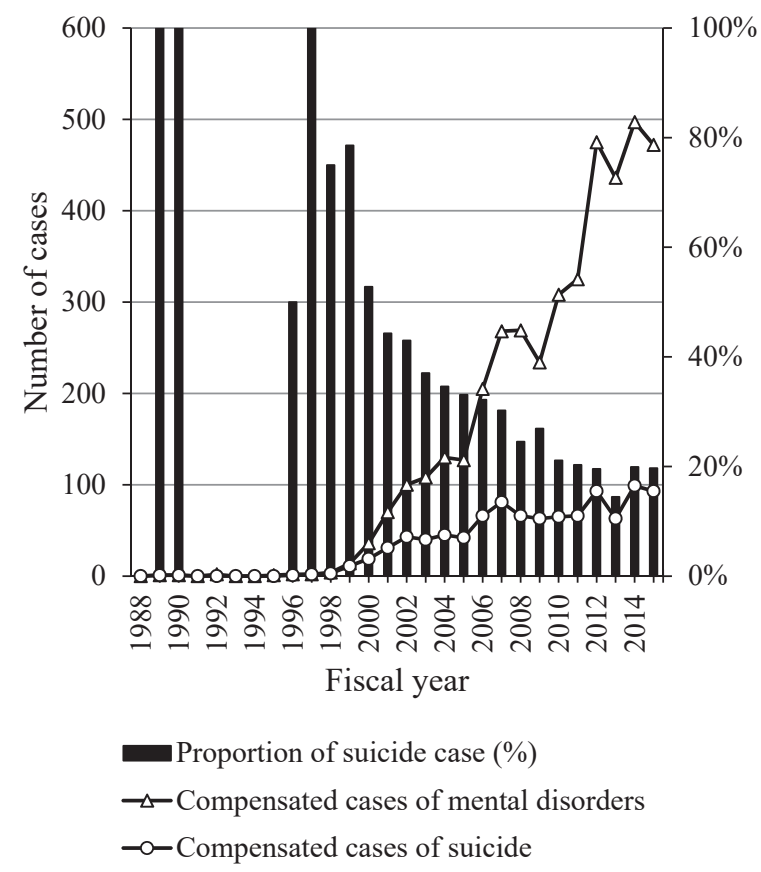

Fig. 3. Proportion of suicide cases among the compensated cases of occupational mental disorders between fiscal years 1988 and 2015.

a detailed analysis of the state of overwork-related disorders in Japan, particularly that in terms of medical diagnosis and industry, had not been carried out. 
Table 1. Objectives of the Principles of Preventive Measures against Overwork-Related Disorders

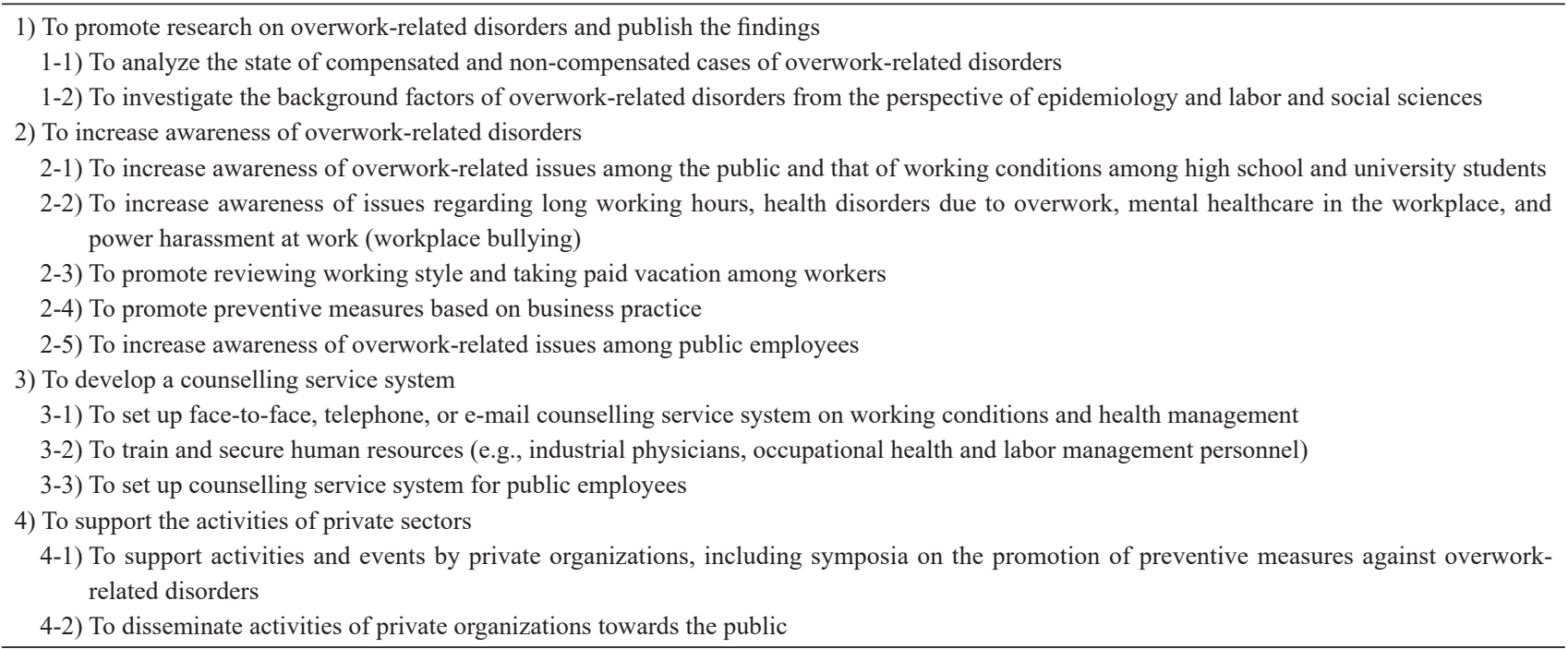

\section{Development of National Prevention Strate- gies for Overwork-related Disorders in Japan}

In response to the situations regarding overwork-related disorders described above and action from relevant people and organizations, including family members of those who died by overwork-related disorders, lawyers, and personnel of non-profit organizations, with more than 500,000 signatories among the general public, a cross-party group of lawmakers of the National Diet of Japan was established to call for a legislation regarding prevention of overworkrelated disorders ${ }^{13)}$. Subsequently, the cross-party group submitted a bill regarding the promotion of preventive measures against overwork-related disorders to the Diet.

In June 2014, the Japanese Government passed the "Act on Promotion of Preventive Measures against Karoshi and Other Overwork-Related Health Disorders" to develop a national initiative of prevention of overwork-related disorders ${ }^{15}$. The Act was enacted in November 2014. In the Act, the term "overwork-related disorders" was defined to include all of the following outcomes: (1) death by CCVD due to overwork, (2) suicide death following an onset of mental disorders due to psychological stress at work, and (3) CCVD due to overwork and mental disorders due to psychological stress at work. It is important to note that the term "overwork-related disorders" defined in the Act includes both fatal and non-fatal outcomes. Subsequently, in July 2015, the "Principles of Preventive Measures against Overwork-Related Disorders" were established under the Act.

The aims of the Act are to clarify the responsibili- ties of the state to promote preventive measures against overwork-related disorders, including a submission of the annual report on the state of and prevention policies regarding overwork-related disorders to the Diet, and to contribute to realizing a society where people can work healthily and actively with an adequate work-life balance. The basic principles of the Act are that (1) research on overwork-related disorders should be conducted to clarify the current state of overwork-related disorders in Japan and to promote preventive measures against overwork-related disorders, (2) preventive measures should be implemented based on the increase in awareness of overwork-related disorders among the public, and (3) comprehensive prevention strategies against overwork-related disorders, which involve central and local governments, employers, and other relevant organizations, are needed.

The Act designates November, which includes the "Labor Thanksgiving Day" in Japan (November 23), as the "Month for Awareness of Prevention of OverworkRelated Disorders", in order to promote public awareness of overwork-related disorders. Furthermore, under the Act, the MHLW established the "Council on Promotion of Preventive Measures against Overwork-Related Disorders". The Council is a regular consultative meeting composed of representatives of (1) those who have suffered from overwork-related disorders and their family members, (2) family members of those who died by overwork-related disorders, (3) employees, (4) employers, and (5) academic experts. As of September 30, 2016, the MHLW has hosted six Councils (two in fiscal year 2014 and four in 2015). The main theme of the Councils was the content of a draft 
of the Principles.

Under the Act, the Cabinet adopted the "Principles of Preventive Measures against Overwork-Related Disorders" in July 2015. The Principles provided a practical framework for preventive measures against overworkrelated disorders (Table 1). Following the statement of the Act, the Principles established the following four major objectives to be implemented by the Japanese Government: (1) to promote research on overwork-related disorders and publish the findings, (2) to increase awareness of overwork-related disorders, (3) to develop a counselling service system, (4) to support the activities of private sectors.

According to the MHLW ${ }^{14)}$, the total national budget for preventive measures against overwork-related disorders (promotion of research, increasing the awareness, development of counselling service, and support for private sectors) was 5.529 billion JPY in fiscal year 2015 and 7.435 billion JPY in fiscal year 2016, respectively (approximately $1 \mathrm{USD}=120 \mathrm{JPY}$ in October 2015).

\section{Analysis of Details about the State of Over- work-related Disorders under the Legal Foundation}

Following the enactment of the Act in November 2014, the Research Center for Overwork-Related Disorders (RECORDS) was established within the National Institute of Occupational Safety and Health, Japan (JNIOSH). To investigate the current situations regarding overworkrelated disorders, the RECORDS collected compensation claims of recognized cases for occupational CCVD and mental disorders from January 2010 through March 2015 and conducted a detailed analysis to characterize the background factors and medical diagnoses relevant to those disorders. Here, we describe the critical results, comparing the state between the cases of CCVD and those of mental disorders. For the findings shown below, ethical approval was obtained from the Institutional Review Board of the National Institute of Occupational Safety and Health, Japan (No. H2708).

\section{Gender and Age}

As shown in Fig. 4-(a) and Fig. 4-(b) ${ }^{16)}$, among those who were determined to be compensated for having occupational CCVD and mental disorders between January 2010 and March 2015, 95.6\% $(1,495 / 1,564)$ of the compensated CCVD cases were male, whereas $68.7 \%$

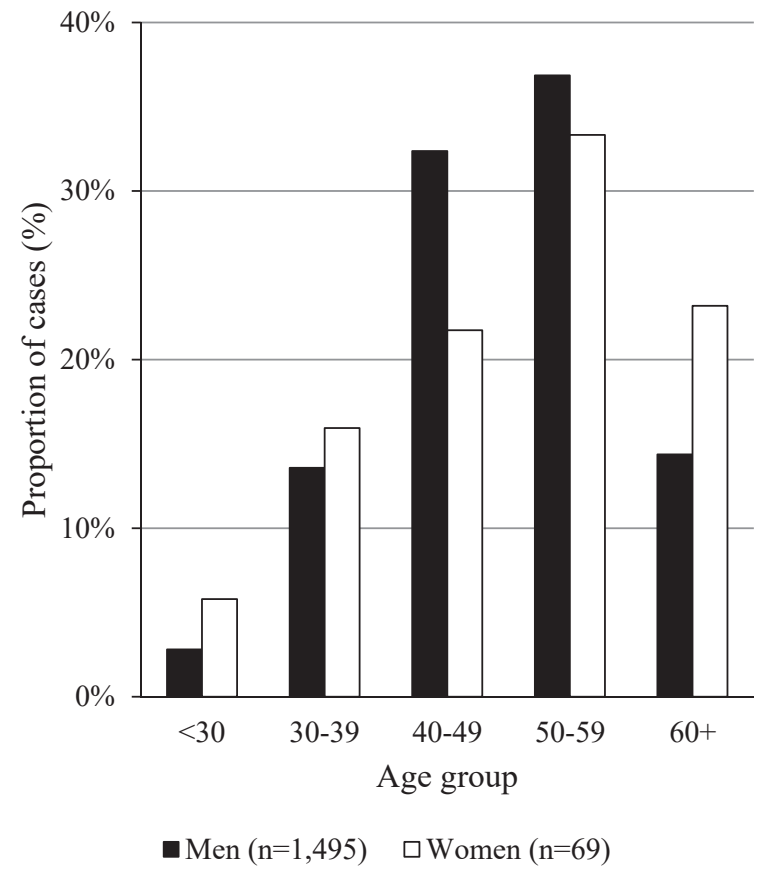

Fig. 4-(a). Distribution of compensated cases of occupational cardiovascular disease by age between January 2010 and March 2015.

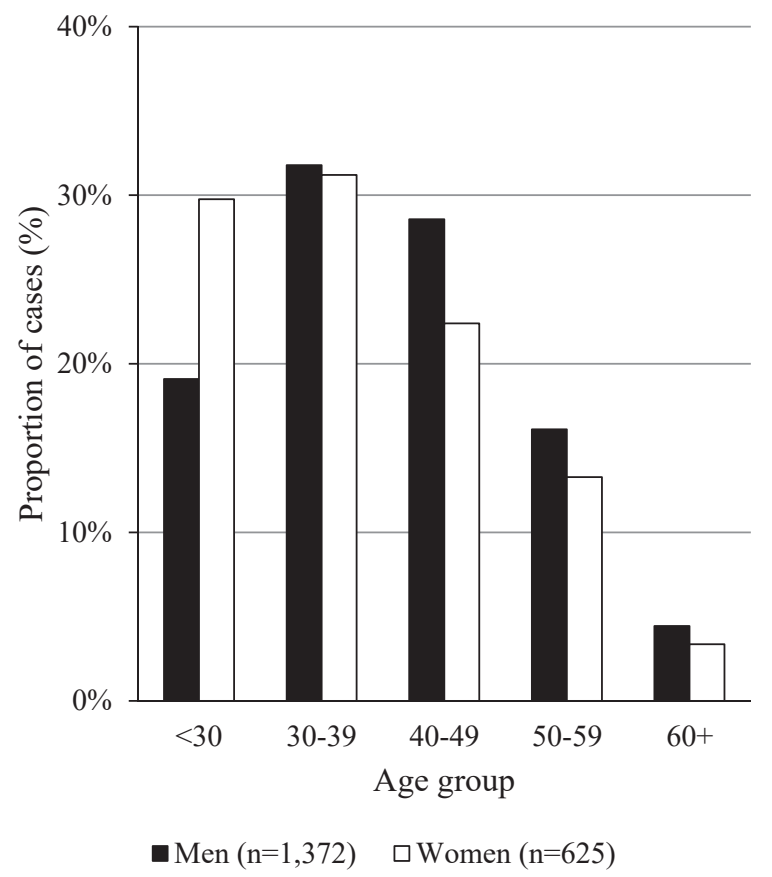

Fig. 4-(b). Distribution of compensated cases of occupational mental disorders by age between January 2010 and March 2015.

$(1,372 / 1,997)$ of the cases of compensated mental disorders were male.

As compared to the age distribution of the onset of com- 


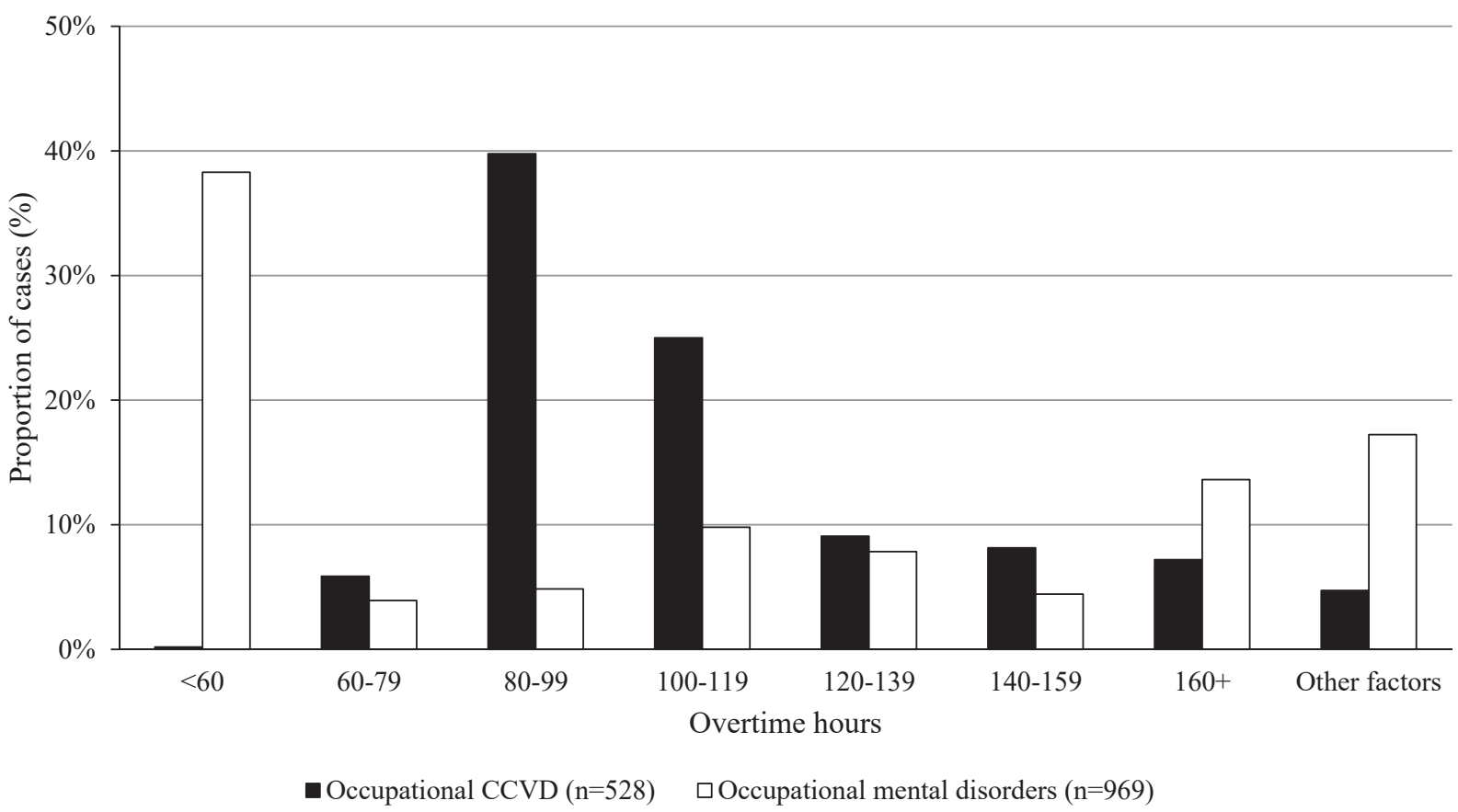

Fig. 5. Distribution of compensated cases of occupational cardiovascular disease and mental disorders by overtime hours in fiscal years 2014 and 2015.

pensated occupational CCVD, occupational mental disorders were compensated more frequently among young people, particularly those aged 30 to $39 \mathrm{yr}$. As depicted in Fig. 4-(b), 50.9\% of male compensated cases of mental disorders and $61.0 \%$ of female cases were their $20 \mathrm{~s}$ or $30 \mathrm{~s}$. The mean age of the onset of compensated CCVD was 49.3 (SD, 9.7) among men and 49.4 (SD, 12.6) among women, whereas that of compensated mental disorders was 40.0 (SD, 11.3) among men and 36.9 (SD, 11.9) among women.

\section{Working Hours and Work Events}

Figure 5 shows the distribution of overtime hours among those who were compensated in fiscal years 2014 and $2015^{9}$. As depicted in Fig. 5, 64.8\% of compensated occupational CCVD cases were confirmed having overtime hours between 80 and $119 \mathrm{~h}$ per month prior to the onset of occupational CCVD. On the other hand, 38.3\% of compensated cases of mental disorders were confirmed having overtime working hours of less than $60 \mathrm{~h}$ per month before the onset, and $17.2 \%$ were compensated due to work-related factors other than long working hours, including exposure to extremely stressful work events, such as severe sexual harassment/violence or accidents in the workplace ${ }^{16)}$.

\section{Job Area/Type}

Tables 2 and 3 depict the distribution of compensated occupational CCVD and mental disorders, respectively, by gender and job area between January 2010 and March $2015^{16)}$. Regarding occupational CCVD (Table 2), among men, $30.7 \%$ of compensated cases were in "transport and postal activities," followed by "wholesale and retail trade" and "manufacturing." In terms of compensated occupational mental disorders (Table 3), among men, "manufacturing" had the largest number of compensated workers, followed by "wholesale and retail trade" and "transport and postal activities." Notably, among women, $28.8 \%$ of compensated cases of occupational mental disorders were in "medical, health and welfare." As suggested in previous literature ${ }^{17)}$, female healthcare professionals, such as nurses in mental health care or caregivers for the elderly, may be more frequently exposed to work-related traumatic events, such as physical assaults and violence from patients and service users. However, regardless of the type of overwork-related disorders (i.e., occupational CCVD or mental disorders), workers in these job areas might not be necessarily compensated more frequently compared to those in other job areas, given the total number of people employed in each job area/industry as the denominator ${ }^{18)}$.

There are some limitations to interpret the values shown 
Table 2. Distribution of compensated cases of cerebrovascular/cardiovascular disease by job category

\begin{tabular}{|c|c|c|c|c|c|c|c|c|c|c|}
\hline \multirow[b]{3}{*}{ Job category (alphabetical order) $)^{\mathrm{e}}$} & \multicolumn{5}{|c|}{ Men } & \multicolumn{5}{|c|}{ Women } \\
\hline & \multicolumn{2}{|c|}{ No. of cases ${ }^{a}$} & \multicolumn{2}{|c|}{$\begin{array}{c}\text { No. of } \\
\text { employee } \\
\text { population } \\
(10,000)^{b, c)}\end{array}$} & \multirow[t]{2}{*}{$\begin{array}{l}\text { No. of cases } \\
\text { per } 1 \text { million }^{\mathrm{d})}\end{array}$} & \multicolumn{2}{|c|}{ No. of cases ${ }^{a)}$} & \multicolumn{2}{|c|}{$\begin{array}{l}\text { No. of } \\
\text { employee } \\
\text { population } \\
(10,000)^{b, c)}\end{array}$} & \multirow[t]{2}{*}{$\begin{array}{l}\text { No. of cases } \\
\text { per } 1 \text { million }^{\mathrm{d})}\end{array}$} \\
\hline & $\mathrm{n}$ & $\%$ & $\mathrm{n}$ & $\%$ & & $\mathrm{n}$ & $\%$ & $\mathrm{n}$ & $\%$ & \\
\hline Accommodations, eating, and drinking services & 104 & $7.0 \%$ & 529 & $4.0 \%$ & 19.7 & 10 & $14.5 \%$ & 986 & $8.9 \%$ & 1.0 \\
\hline Agriculture and forestry & 6 & $0.4 \%$ & 148 & $1.1 \%$ & 4.1 & 1 & $1.4 \%$ & 111 & $1.0 \%$ & 0.9 \\
\hline Compound services & 6 & $0.4 \%$ & 147 & $1.1 \%$ & 4.1 & 1 & $1.4 \%$ & 98 & $0.9 \%$ & 1.0 \\
\hline Construction & 162 & $10.8 \%$ & 1,448 & $10.9 \%$ & 11.2 & 0 & $0.0 \%$ & 243 & $2.2 \%$ & 0.0 \\
\hline Education, learning support & 23 & $1.5 \%$ & 613 & $4.6 \%$ & 3.8 & 2 & $2.9 \%$ & 704 & $6.4 \%$ & 0.3 \\
\hline Electricity, gas, heat supply, and water & 1 & $0.1 \%$ & 134 & $1.0 \%$ & 0.7 & 0 & $0.0 \%$ & 19 & $0.2 \%$ & 0.0 \\
\hline Finance and insurance & 9 & $0.6 \%$ & 333 & $2.5 \%$ & 2.7 & 1 & $1.4 \%$ & 400 & $3.6 \%$ & 0.3 \\
\hline Fisheries & 14 & $0.9 \%$ & 26 & $0.2 \%$ & 53.8 & 0 & $0.0 \%$ & 6 & $0.1 \%$ & 0.0 \\
\hline Information and communications & 46 & $3.1 \%$ & 610 & $4.6 \%$ & 7.5 & 5 & $7.2 \%$ & 215 & $2.0 \%$ & 2.3 \\
\hline Living-related, personal, and amusement services & 33 & $2.2 \%$ & 332 & $2.5 \%$ & 9.9 & 4 & $5.8 \%$ & 523 & $4.7 \%$ & 0.8 \\
\hline Manufacturing & 186 & $12.4 \%$ & 3,263 & $24.5 \%$ & 5.7 & 7 & $10.1 \%$ & 1,359 & $12.3 \%$ & 0.5 \\
\hline Medical, health, and welfare & 38 & $2.5 \%$ & 709 & $5.3 \%$ & 5.4 & 11 & $15.9 \%$ & 2,563 & $23.3 \%$ & 0.4 \\
\hline Mining and quarrying of stone and gravel & 0 & $0.0 \%$ & 12 & $0.1 \%$ & 0.0 & 0 & $0.0 \%$ & 3 & $0.0 \%$ & 0.0 \\
\hline Real estate and goods rental and leasing & 28 & $1.9 \%$ & 236 & $1.8 \%$ & 11.9 & 0 & $0.0 \%$ & 140 & $1.3 \%$ & 0.0 \\
\hline $\begin{array}{l}\text { Scientific research, professional, and technical } \\
\text { services }\end{array}$ & 44 & $2.9 \%$ & 417 & $3.1 \%$ & 10.6 & 3 & $4.3 \%$ & 249 & $2.3 \%$ & 1.2 \\
\hline Services, N.E.C. & 121 & $8.1 \%$ & 1,091 & $8.2 \%$ & 11.1 & 4 & $5.8 \%$ & 815 & $7.4 \%$ & 0.5 \\
\hline Transport and postal activities & 459 & $30.7 \%$ & 1,272 & $9.5 \%$ & 36.1 & 6 & $8.7 \%$ & 292 & $2.6 \%$ & 2.1 \\
\hline Wholesale and retail trade & 215 & $14.4 \%$ & 2,005 & $15.0 \%$ & 10.7 & 14 & $20.3 \%$ & 2,296 & $20.8 \%$ & 0.6 \\
\hline Total & 1,495 & $100 \%$ & 13,325 & $100 \%$ & 11.2 & 69 & $100 \%$ & 11,022 & $100 \%$ & 0.6 \\
\hline
\end{tabular}

a) Total number of cases that were determined to be compensated between January 2010 and March 2015. This column includes the cases that were claimed to workers' compensation before December 2009.

b) Data from the Labour Force Survey, Ministry of Internal Affairs and Communications of Japan.

c) Total population of employees (annual average) in Japan between January 2010 and December 2014. These figures include both full-time and part-time employees.

d) Due to the unavailability of data on the population of employees between January 2015 and March 2015, the compensation rates in this column are slightly higher than the actual value.

e) Public employees and central and local government officers are not included.

in Tables 2 and 3. For instance, due to the unavailability of data on the population of employees between January 2015 and March 2015, the compensation rates are slightly higher than the actual value.

\section{Medical Diagnoses}

Table 4 shows the distribution of diagnoses among compensated cases of occupational CCVD by gender between January 2010 and March $2015^{16)}$. While $60.5 \%$ of male compensated cases had been diagnosed as having cerebrovascular diseases, particularly intracerebral hemorrhage, $91.3 \%$ of female compensated cases had been diagnosed having cerebrovascular diseases.

Table 5 summarizes the distribution of diagnoses among compensated cases of occupational mental disorders by gender between January 2010 and March $2015^{16)}$. Notably,
$59.7 \%$ of male compensated cases had been diagnosed as having mood (affective) disorders. Among women, 73.0\% of compensated cases had been diagnosed having neurotic, stress-related, or somatoform disorders, particularly posttraumatic stress disorder (PTSD).

\section{Conclusion}

In the current paper, we briefly analyzed the characteristics of compensated occupational CCVD and mental disorders due to overwork or psychological stress at work. Over the past decade, the number of claims, as well as that of compensation, of occupational mental disorders have been substantially increasing, as compared to those of occupational CCVD. Notably, among the cases of compensated occupational mental disorders, approximately $50 \%$ of male and $60 \%$ of female cases were in their $20 \mathrm{~s}$ or $30 \mathrm{~s}$. 
Table 3. Distribution of compensated cases of mental disorders by job category

\begin{tabular}{|c|c|c|c|c|c|c|c|c|c|c|}
\hline \multirow[b]{3}{*}{ Job category (alphabetic order) ${ }^{\mathrm{e})}$} & \multicolumn{5}{|c|}{ Men } & \multicolumn{5}{|c|}{ Women } \\
\hline & \multicolumn{2}{|c|}{ No. of cases ${ }^{\text {a) }}$} & \multicolumn{2}{|c|}{$\begin{array}{c}\text { No. of } \\
\text { employee } \\
\text { population } \\
\left.(10,000)^{\mathrm{b}, \mathrm{c}}\right)\end{array}$} & \multirow[t]{2}{*}{$\begin{array}{l}\text { No. of cases } \\
\text { per } 1 \text { million }^{\mathrm{d})}\end{array}$} & \multicolumn{2}{|c|}{ No. of cases ${ }^{\text {a) }}$} & \multicolumn{2}{|c|}{$\begin{array}{c}\text { No. of } \\
\text { employee } \\
\text { population } \\
(10,000)^{\mathrm{b}, \mathrm{c})}\end{array}$} & \multirow[t]{2}{*}{$\begin{array}{l}\text { No. of cases } \\
\text { per } 1 \text { million }^{\text {d) }}\end{array}$} \\
\hline & $\mathrm{n}$ & $\%$ & $\mathrm{n}$ & $\%$ & & $\mathrm{n}$ & $\%$ & $\mathrm{n}$ & $\%$ & \\
\hline Accommodations, eating, and drinking services & 87 & $6.3 \%$ & 529 & $4.0 \%$ & 16.4 & 48 & $7.7 \%$ & 986 & $8.7 \%$ & 4.9 \\
\hline Agriculture and forestry & 15 & $1.1 \%$ & 148 & $1.1 \%$ & 10.1 & 2 & $0.3 \%$ & 111 & $1.0 \%$ & 1.8 \\
\hline Compound services & 10 & $0.7 \%$ & 147 & $1.1 \%$ & 6.8 & 7 & $1.1 \%$ & 98 & $0.9 \%$ & 7.1 \\
\hline Construction & 138 & $10.1 \%$ & 1,448 & $10.9 \%$ & 9.5 & 11 & $1.8 \%$ & 243 & $2.2 \%$ & 4.5 \\
\hline Education, learning support & 32 & $2.3 \%$ & 613 & $4.6 \%$ & 5.2 & 25 & $4.0 \%$ & 704 & $6.2 \%$ & 3.6 \\
\hline Electricity, gas, heat supply, and water & 12 & $0.9 \%$ & 134 & $1.0 \%$ & 9.0 & 1 & $0.2 \%$ & 19 & $0.2 \%$ & 5.3 \\
\hline Finance and insurance & 23 & $1.7 \%$ & 333 & $2.5 \%$ & 6.9 & 30 & $4.8 \%$ & 400 & $3.5 \%$ & 7.5 \\
\hline Fisheries & 6 & $0.4 \%$ & 26 & $0.2 \%$ & 23.1 & 0 & $0.0 \%$ & 6 & $0.1 \%$ & 0.0 \\
\hline Information and communications & 97 & $7.1 \%$ & 610 & $4.6 \%$ & 15.9 & 28 & $4.5 \%$ & 215 & $1.9 \%$ & 13.0 \\
\hline Living-related, personal, and amusement services & 30 & $2.2 \%$ & 332 & $2.5 \%$ & 9.0 & 15 & $2.4 \%$ & 523 & $4.6 \%$ & 2.9 \\
\hline Manufacturing & 290 & $21.1 \%$ & 3,263 & $24.5 \%$ & 8.9 & 59 & $9.5 \%$ & 1,359 & $12.0 \%$ & 4.3 \\
\hline Medical, health, and welfare & 51 & $3.7 \%$ & 709 & $5.3 \%$ & 7.2 & 179 & $28.8 \%$ & 2,563 & $22.7 \%$ & 7.0 \\
\hline Mining and quarrying of stone and gravel & 3 & $0.2 \%$ & 12 & $0.1 \%$ & 25.0 & 0 & $0.0 \%$ & 3 & $0.0 \%$ & 0.0 \\
\hline Real estate and goods rental and leasing & 39 & $2.8 \%$ & 236 & $1.8 \%$ & 16.5 & 13 & $2.1 \%$ & 140 & $1.2 \%$ & 9.3 \\
\hline $\begin{array}{l}\text { Scientific research, professional, and technical } \\
\text { services }\end{array}$ & 70 & $5.1 \%$ & 417 & $3.1 \%$ & 16.8 & 22 & $3.5 \%$ & 249 & $2.2 \%$ & 8.8 \\
\hline Services, N.E.C. & 100 & $7.3 \%$ & 1,091 & $8.2 \%$ & 9.2 & 45 & $7.2 \%$ & 815 & $7.2 \%$ & 5.5 \\
\hline Transport and postal activities & 176 & $12.8 \%$ & 1,272 & $9.5 \%$ & 13.8 & 38 & $6.1 \%$ & 292 & $2.6 \%$ & 13.0 \\
\hline Wholesale and retail trade & 193 & $14.1 \%$ & 2,005 & $15.0 \%$ & 9.6 & 97 & $15.6 \%$ & 2,296 & $20.3 \%$ & 4.2 \\
\hline Total & 1,372 & $100 \%$ & 13,325 & $100 \%$ & 10.3 & 620 & $100 \%$ & 11,022 & $100 \%$ & 5.6 \\
\hline
\end{tabular}

a) Total number of cases that were determined to be compensated between January 2010 and March 2015. This column includes the cases that were claimed to workers' compensation before December 2009.

b) Data from the Labour Force Survey, Ministry of Internal Affairs and Communications of Japan.

c) Total population of employees (annual average) in Japan between January 2010 and December 2014. These figures include both full-time and part-time employees.

d) Due to the unavailability of data on the population of employees between January 2015 and March 2015, the compensation rates in this column are slightly higher than the actual value.

e) Public employees and central and local government officers are not included.

Table 4. Distribution of diagnosis of occupational cerebrovascular/ cardiovascular disease by gender

\begin{tabular}{lrrrrrr}
\hline & \multicolumn{2}{c}{$\begin{array}{c}\text { Men } \\
(\mathrm{n}=1,495)\end{array}$} & & \multicolumn{2}{c}{$\begin{array}{c}\text { Women } \\
(\mathrm{n}=69)\end{array}$} \\
\cline { 2 - 3 } \cline { 6 - 7 } & $\mathrm{n}$ & $\mathrm{SD} / \%$ & & $\mathrm{n}$ & $\mathrm{SD} / \%$ \\
\hline Age of onset (Mean, SD) & 49.3 & 9.7 & & 49.4 & 12.6 \\
Cerebrovascular diseases & & & & & \\
$\quad$ Intracerebral hemorrhage & 419 & $28.0 \%$ & & 28 & $40.6 \%$ \\
$\quad$ Subarachnoid hemorrhage & 261 & $17.5 \%$ & & 28 & $40.6 \%$ \\
$\quad$ Cerebral infarction & 221 & $14.8 \%$ & & 7 & $10.1 \%$ \\
$\quad$ Hypertensive encephalopathy & 4 & $0.3 \%$ & & 0 & - \\
Cardiovascular diseases & & & & & \\
$\quad$ Myocardial infarction & 267 & $17.9 \%$ & & 1 & $1.4 \%$ \\
$\quad$ Cardiac arrest & 220 & $14.7 \%$ & & 4 & $5.8 \%$ \\
$\quad$ Dissecting aneurysm & 81 & $5.4 \%$ & & 1 & $1.4 \%$ \\
$\quad$ Angina pectoris & 19 & $1.3 \%$ & & 0 & - \\
Other diseases (e.g., epilepsy) & 3 & $0.2 \%$ & & 0 & - \\
\hline
\end{tabular}

Table 5. Distribution of diagnosis of occupational mental disorders by gender

\begin{tabular}{lrrrrrr}
\hline & \multicolumn{2}{c}{ Men } & & \multicolumn{2}{c}{ Women } \\
& \multicolumn{1}{c}{$(\mathrm{n}=1,373)$} & & \multicolumn{2}{c}{$(\mathrm{n}=627)$} \\
\cline { 2 - 3 } \cline { 5 - 6 } & $\mathrm{n}$ & $\mathrm{SD} / \%$ & & $\mathrm{n}$ & $\mathrm{SD} / \%$ \\
\hline Age of onset (Mean, SD) & 40.0 & 11.3 & & 36.9 & 11.9 \\
F3 (Mood (affective) disorders) & 820 & $59.7 \%$ & & 169 & $27.0 \%$ \\
$\quad$ F32 (Depressive episode) & 716 & $52.1 \%$ & & 151 & $24.1 \%$ \\
$\quad$ Other F3 & 104 & $7.6 \%$ & & 18 & $2.9 \%$ \\
F4 (Neurotic, stress-related and somato- & 540 & $39.3 \%$ & & 458 & $73.0 \%$ \\
form disorders) & 39 & $2.8 \%$ & & 61 & $9.7 \%$ \\
$\quad$ F43.0 (Acute stress reaction) & 145 & $10.6 \%$ & & 163 & $26.0 \%$ \\
$\quad$ F43.1 (Post-traumatic stress disorder) & 228 & $16.6 \%$ & & 129 & $20.6 \%$ \\
F43.2 (Adjustment disorders) & 128 & $9.3 \%$ & & 105 & $16.7 \%$ \\
$\quad$ Other F4 & 13 & $0.9 \%$ & & 0 & - \\
Other mental disorders & & & &
\end{tabular}


These findings suggest the importance of promoting mental health-related support for young employees, as well as increasing awareness of working conditions among students.

In fiscal year 2015 (i.e., the first full fiscal year after the Act was enacted in November 2014), the number of claims for workers' compensation of both occupational CCVD and mental disorders in Japan increased slightly from the previous year (Fig. 1-(a) and Fig. 1-(b)). This may be due to increased awareness of overwork-related disorders and workers' compensation system for occupational CCVD and mental disorders, because the enactment of the Act, along with the recent situation regarding overwork-related disorders, were widely reported by the media in Japan.

The term karoshi firstly appeared in Japan in the late 1970s. To our knowledge, Japan was the first country to pass a law specifically focusing on comprehensive preventive measures against overwork-related disorders. Overwork-related disorders have been a major occupational and public health issue in both developed and developing countries. Thus, experience in Japan can provide other countries with useful information on developing a national preventive policy against overwork-related disorders. Changes in the trend of overwork-related disorders in Japan under a legal foundation and an initiative by the central government should be closely monitored, so that other countries can benefit from the experiences. Additionally, the long-term effect of preventive measures based on the Act and the Principles (i.e., preventive efforts regarding increasing the awareness, development of counselling service, and support for private sectors) should be evaluated.

\section{Acknowledgements}

We would like to thank Dr. Shigeki Koda, Deputy Director-General of the National Institute of Occupational Safety and Health, Japan, for providing administrative support and important discussion. We also thank the staff at the Research Center for Overwork-Related Disorders, National Institute of Occupational Safety and Health, Japan, for their support with data collection.

This work was supported by the Industrial Disease Clinical Research Grants from the Ministry of Health, Labour and Welfare, Government of Japan (150903-01).

\section{Disclaimer}

The content of this paper reflects the views of the authors and does not necessarily reflect the views and poli- cies of the Ministry of Health, Labour and Welfare, Government of Japan, or the National Institute of Occupational Safety and Health, Japan. The translation of the names of proper nouns, such as the name of an act, from Japanese into English language was made by the authors and is not an official translation by the Government of Japan.

\section{References}

1) Bannai A, Tamakoshi A (2014) The association between long working hours and health: a systematic review of epidemiological evidence. Scand J Work Environ Health 40, 5-18. [Medline] [CrossRef]

2) Cheng Y, Park J, Kim Y, Kawakami N (2012) The recognition of occupational diseases attributed to heavy workloads: experiences in Japan, Korea, and Taiwan. Int Arch Occup Environ Health 85, 791-9. [Medline] [CrossRef]

3) Iwasaki K, Takahashi M, Nakata A (2006) Health problems due to long working hours in Japan: working hours, workers' compensation (Karoshi), and preventive measures. Ind Health 44, 537-40. [Medline] [CrossRef]

4) Statistics Bureau, Ministry of Internal Affairs and Communications, Government of Japan. Labour Force Survey. http:// www.e-stat.go.jp/SG1/estat/ListE.do?lid $=000001143324$. Accessed August 15, 2016.

5) International Labour Organization. ILOSTAT Database. http://www.ilo.org/ilostat/. Accessed on the same day.

6) The Japan Institute for Labour Policy and Training. Databook of international labour statistics 2016 (in Japanese). http://www.jil.go.jp/english/estatis/databook/2016/index. html. Accessed August 15, 2016.

7) National Police Agency, Government of Japan. Toukei (in Japanese). https://www.npa.go.jp/toukei/index.htm. Accessed August 15, 2016.

8) Cabinet Office, Government of Japan. 2013 White paper on suicide prevention (in Japanese). http:/www8.cao.go.jp/ jisatsutaisaku/whitepaper/index-w.html. Accessed August 15, 2016.

9) Ministry of Health, Labour and Welfare, Government of Japan. Heisei 27 nendo karoshi-tou no rousai hosyou jyoukyou wo kouhyou. http://www.mhlw.go.jp/stf/houdou/ 0000128216.html. Accessed August 15, 2016.

10) Eguchi H, Wada K, Smith DR (2016) Recognition, compensation, and prevention of karoshi, or death due to overwork. J Occup Environ Med 58, e313-4. [Medline] [CrossRef]

11) Nishiyama K, Johnson JV (1997) Karoshi — death from overwork: occupational health consequences of Japanese production management. Int J Health Serv 27, 625-41. [Medline] [CrossRef]

12) Ministry of Health, Labour and Welfare, Government of Japan. Kokoro no mimi (in Japanese). http://kokoro.mhlw. go.jp/case/worker/000615.html. Accessed August 15, 2016.

13) Kawahito H, Karojisatsu (in Japanese). 2014, Tokyo: Iwanami Shoten. 
14) Ministry of Health, Labour and Welfare, Government of Japan. 2016 White paper on preventive measures against overwork-related disorders (Karoshi tou boushi taisaku hakusyo) (in Japanese). http://www.mhlw.go.jp/wp/ hakusyo/karoushi/16/index.html. Accessed December 1, 2016.

15) Ministry of Health, Labour and Welfare, Government of Japan. Karoshi tou boushi taisaku ni kansuru hourei (in Japanese). http://www.mhlw.go.jp/stf/seisakunitsuite/ bunya/0000053525.html. Accessed August 15, 2016.

16) Takahashi M (Principal Investigator). Comprehensive study for the current status and preventive strategies of overworkrelated disorders (in Japanese). http://www.mhlw.go.jp/ seisakunitsuite/bunya/koyou_roudou/roudoukijun/rousai/ hojokin/0000051158.html. Accessed December 1, 2016.

17) Skogstad M, Skorstad M, Lie A, Conradi HS, Heir T, Weisæth L (2013) Work-related post-traumatic stress disorder. Occup Med (Lond) 63, 175-82. [Medline] [CrossRef]

18) Statistics Bureau, Ministry of Internal Affairs and Communications, Government of Japan. Heisei 27-nen roudouryoku cyousa nenpou (in Japanese). http://www.stat.go.jp/data/ roudou/report/2015/index.htm. Accessed August 15, 2016. 